Available online on 15.3.2018 at http://ujpr.org
Universal Journal of Pharmaceutical Research
An International Peer Reviewed Journal
Open access to Pharmaceutical research is an open access article distributed under the terms of the Creative Commons Attribution-Non
Commercial Share Alike 4.0 License which permits unrestricted non commercial use,
provided the original work is properly cited
Volume 3, Issue 1, 2018

\title{
EVALUATION OF FACTORS AFFECTING EFFICIENCY AND EFFECTIVENESS AMONG STAFFS OF SHIRAZ UNIVERSITY OF MEDICAL SCIENCE

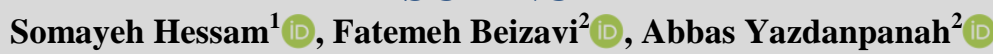 \\ ${ }^{I}$ Department of Health Services Administration, South Tehran branch, Islamic Azad University, Tehran, Iran. ${ }^{2}$ Department of Healthcare Management, Marvdasht Branch, Islamic Azad University, Marvdasht, Iran.
}

\section{ABSTRACT}

Objectives: The general goal of present research is to study factors affecting improvement of efficiency and effectiveness among staffs of Shiraz University of medical science. This is an applied research in terms of objective and this is a descriptive co relational research in terms of information collection. Information was collected by library in field form.

Methods: Statistical population includes all personnel of Shiraz University of medical science (900 people). Concerning Cochran's table, the number of samples was 269. The simple random sampling was used. The researcher-conducted questionnaire has been used to collect information and to study factors affecting the improvement of efficiency and effectiveness among personnel of Shiraz University of medical science. The questionnaires were designed based on Five-point Likert scale and the questionnaire contains 27 items. The validity and reliability of the questionnaire were confirmed. Various statistical methods have been applied to analyze data resulted from the questionnaire. Descriptive statistical method, relative frequency distribution table and percentage diagrams have been used in descriptive part of the research. Kolmogorov-Smirnov, Pearson correlation as well as Friedman tests have been used to study data normality in inferential statistical section.

Results: Results indicated that there was a significant relationship between organizational culture, incentive, technological factors, staffs' training and the effectiveness and efficiency of personnel of Shiraz University of medical science. The sequence of efficiency indicators of personnel of Shiraz University of medical science shows that organizational culture of personnel of Shiraz University of medical science is in the first place using Friedman test. Incentive, technological factors and staff training are in the second, third and fourth place respectively. Furthermore, Friedman test of the sequence of effectiveness indicators of personnel of Shiraz University of medical science indicates that technology with mean of 5 is in the first place. Incentive, staff training and organizational culture are in the second, third and fourth place respectively.

Conclusion: It is suggested that indicators of organizational culture and technology are paid attention by authorities for organizational effectiveness and efficiency.

Keywords: Effectiveness, improvement of efficiency, organizational culture, personnel of Shiraz University of medical science, technology.

Article Info: Received 29 September 2017; Revised 12 January; Accepted 20 February, Available online 15 March 2018

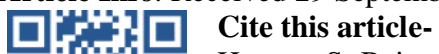

Hessam S, Beizavi F, Yazdanpanah A. Evaluation of factors affecting efficiency and effectiveness among staffs of Shiraz University of medical science Universal Journal of Pharmaceutical Research. 2018; 3(1): 1-6. DOI: http://doi.org/10.22270/ujpr.v3i1.R1

Address for Correspondence:

Somayeh Hessam, Department of Health Services Administration, South Tehran branch, Islamic Azad University, Tehran, Iran. E-mail: somayehh59@yahoo.com

\section{INTRODUCTION}

Human source is considered as one of valuable organizational capitals, the most important competitive advantage and the rarest source in knowledge-based economy ${ }^{1-4}$. This is the most important organizational capital due to its considerable effect on organizational effectiveness. Nowadays, organizations and managers are trying to attract the best and the most expert human sources using different strategies and approaches ${ }^{5}$. Social nature of human being causes it to communicate with different aspects of society and other groups. In such societies, communication is one of the most important factors for development, promotion and success of human being ${ }^{6-12}$. Organizational effectiveness is a concept by which the organization meets its goals using special sources without wasting sources as well as without destroying the members of society. In fact, organizational effectiveness shows how much the organization is closed to its goals. In other words, it shows how the organization realizes its goals $^{13}$. In literature of management, effectiveness is defined as performing right tasks and efficiency is 
defined as performing works truly. The concept of effectiveness is inside the concept of efficiency. Effectiveness should be defined necessarily in the framework of a certain program which is under evaluation. Effectiveness means to study effectiveness of measures taken for reaching pre-determined goals. In other words, the goals' realization is measured in an effectiveness research. But, it seems that we should step further to define the concept of effectiveness meaning that effectiveness is gained in an educational period when first, educational requirements are recognized clearly. Second, an appropriate program should be designed to meet needs. Third, such program should be implemented correctly. Fourth, the educational process as well as targets should be evaluated properly ${ }^{7}$. An important point about effectiveness is that the educational process and its realization should be considered correctly before studying how to measure targets. Studying the history of quality shows that in the past not so long ago, producers considered inspection of finished product to ensure the quality. Inspection was done when the product was produced and there was no opportunity for solving possible errors. When quality security was outlined, the quality and its security were dealt in different processes of the production. It is also the case in educational effectiveness. It means that absolute measurement of effectiveness at the end of educational period is not a complete approach. Educational effectiveness and quality should be created and ensured during educational process then; they should be studied and measured at the end of process to ensure correct measures and goal realization ${ }^{6}$. The organization, as a social institution, makes a kind of organizational relationship among people beyond routine communications due to fundamental goals. It is evident that managers pay attention to such communications and how they are oriented to organizational goals. Managers found that effective relationship with human sources as well as perception of relational motivations of staff are effective factors on reaching predetermined goals of the organization ${ }^{10}$ Ebrahimnejad et al., studied the relationship between strategic-expert knowledge share and productivity indicators of effectiveness and efficiency in insurance companies of Khorasan ${ }^{1}$. He came up with the conclusion that there was a positive and significant relationship between strategic-expert knowledge share and productivity indicators of effectiveness and efficiency. Therefore, it seems that favorable use of strategic-expert knowledge share can increase productivity of insurance industry. Hosseini et al., studied the relationship between moral behavior and organizational efficiency and effectiveness ${ }^{3}$. He concluded that moral behaviors increased organizational efficiency and effectiveness as well as organizational health and they reduced corruption. Salamati et al., studied factors affecting effectiveness and efficiency of staffs and managers from view of change-based thought ${ }^{5}$. The statistical population was 221 employees of national bank of Miandoab. The sample size was 120 people who were chosen randomly. It was a descriptive analysis and Pearson correlation test has been used. There was a significant relationship between factors affecting efficiency and effectiveness from thinking view. Therefore, the present research aims to study factors affecting improvement of organizational efficiency and effectiveness among personnel of Shiraz University of medical science. The present research is going to answer following question: what factors are effective on improvement of efficiency and effectiveness of personnel of Shiraz University of medical science? How factors affecting improvement of efficiency and effectiveness among personnel of Shiraz University of medical science are prioritized from viewpoints of personnel of Shiraz University of medical science

\section{METHODS}

This is a descriptive-surveying research and statistical population includes all personnel of Shiraz University of medical science (900 people). To determine the sample size, Cochran table was used. Concerning Cochran table, 269 samples were chosen among 5105 persons. The simple random sampling was applied. The researcher-conducted questionnaire was used as the measuring instrument based on theoretical framework. The questionnaires were designed based on five-point Likert scale including 5 ranges (very low, low, average, high, and very high). The scores of $1,2,3,4$, and 5 were allocated ranging from very low to very high. The questionnaire contains 27 items. Face validity of items was confirmed by professors and construct validity of the questionnaire was confirmed via exploratory factor analysis. The questionnaire's reliability was obtained by Cronbach's coefficient alpha. Therefore, total reliability coefficient was obtained as 0.87 . Results have been analyzed by SPSS and descriptive and inferential statistics were used.

Table 1: Correlation coefficient of research hypotheses.

\begin{tabular}{cccccc}
\hline Factors affecting efficiency & $\begin{array}{c}\text { Organizational } \\
\text { culture }\end{array}$ & Incentive & Technology & $\begin{array}{c}\text { Staffs' } \\
\text { training }\end{array}$ \\
\hline Efficiency & $\begin{array}{c}\text { Pearson } \\
\text { correlation } \\
\text { coefficient }\end{array}$ & 0.959 & 0.907 & 0.897 & 0.774 \\
\cline { 2 - 6 } & $\begin{array}{c}\text { Significance } \\
\text { level }\end{array}$ & 0.000 & 0.000 & 0.000 & 0.000 \\
\hline
\end{tabular}

\section{RESULTS AND DISCUSSION}

As seen in Table 1, following variables play role respectively in factors affecting efficiency. First, organizational culture of personnel of Shiraz
University of medical science had the highest effect (correlation coefficient: 0.959) on efficiency. The second variable is incentive with correlation coefficient of 0.907 . The third variable is technology with 
correlation coefficient of 0.897 . The fourth variable is staffs' training with correlation coefficient of 0.774. All above variables had direct significant relationship with efficiency. As seen in Table 2, following variables play role in staffs' effectiveness. First, organizational culture of personnel of Shiraz University of medical science had the highest effect (correlation coefficient:
0.938) on effectiveness. The second variable is technology with correlation coefficient of 0.924 . The third variable is incentive with correlation coefficient of 0.915 . The fourth variable is staffs' training with correlation coefficient of 0.820 . All above variables had direct significant relationship with effectiveness.

Table 2: Correlation coefficient of research hypotheses.

\begin{tabular}{lccccc}
\hline \multicolumn{2}{l}{ Factors affecting effectiveness } & $\begin{array}{c}\text { Organizational } \\
\text { culture }\end{array}$ & Incentive & Technology & $\begin{array}{c}\text { Staffs' } \\
\text { training }\end{array}$ \\
\hline $\begin{array}{l}\text { Staffs' } \\
\text { effectiveness }\end{array}$ & $\begin{array}{c}\text { Pearson } \\
\text { correlation } \\
\text { coefficient }\end{array}$ & 0.938 & 0.915 & 0.924 & 0.820 \\
\cline { 2 - 6 } & $\begin{array}{c}\text { Significance } \\
\text { level }\end{array}$ & 0.000 & 0.000 & 0.000 & 0.000 \\
\hline
\end{tabular}

Now, indicators of efficiency and effectiveness of personnel of Shiraz University of medical science are organized according to importance. According to Table 3 , priority of efficiency indicators of personnel of Shiraz University of medical science (using Friedman test) shows that organizational culture of personnel of Shiraz University of medical science (mean of 4) obtained the first place. Incentive (2.98), technological factors (2.02) and staffs' training (1) obtained respectively the second to the fourth places. The significance level of efficiency and effectiveness indicators of personnel of Shiraz University of medical science was equal to 0.000 and it was significant at $95 \%$ level and the amount of $\mathrm{X}^{2}$ was 697.282 .
In this section, the ranks and priority of effectiveness indicators of personnel of Shiraz University of medical science are addressed. In Table 4, the priority of effectiveness indicator of personnel of Shiraz University of medical science (using Freidman test) shows that among research variables, technology with mean of 5 , incentive with mean of 3.59, staffs' training with mean of 2.86 and organizational culture with mean of 2.19 were respectively in the first, second, third, fourth places. The significance level of effectiveness indicator of personnel of Shiraz University of medical science was equal to 0.000 in $95 \%$ level. The amount of $\mathrm{X}^{2}$ was equal to 913.795 .

Table 3: The ranks of efficiency indicators of personnel of Shiraz University of medical science.

\begin{tabular}{|c|c|c|c|c|c|}
\hline $\begin{array}{l}\text { Efficiency } \\
\text { indicator }\end{array}$ & Rank & $\begin{array}{c}\text { Mean } \\
\text { rank }\end{array}$ & $\begin{array}{c}\text { Freedom } \\
\text { degree }\end{array}$ & $\mathbf{X}^{2}$ & $\begin{array}{c}\begin{array}{c}\text { Significance } \\
\text { level }\end{array} \\
\end{array}$ \\
\hline $\begin{array}{l}\text { Organizational } \\
\text { culture }\end{array}$ & 1 & 4 & 3 & 697.282 & 0.000 \\
\hline Incentive & 2 & 2.98 & & & \\
\hline Technology & 3 & 2.02 & & & \\
\hline Staffs' training & 4 & 1 & & & \\
\hline
\end{tabular}

\section{CONCLUSION}

The present research aims to answer following hypotheses:

Hypothesis 1: organizational culture has a significant effect on improvement of efficiency of personnel of Shiraz University of medical science. Correlation coefficient of the variables is 0.959 and their significance level is 0.000 which is below 0.01. Such hypothesis is confirmed by $99 \%$. Therefore, there is a significant relationship between organizational culture and efficiency of personnel of Shiraz University of medical science. H0 is rejected and H1 is confirmed. Thus, improvement of organizational culture increases efficiency of personnel of Shiraz University of medical science. The result is consistent with following researches: Mahanaty et al., studied the effect of organizational culture on organizational efficiency and effectiveness ${ }^{11}$. The paper evaluated the pressure of organizational culture on organizational effectiveness and efficiency. The evaluation of organizational culture of three different organizations showed that organizational culture can stimulate efficiency and effectiveness in organizations by different ways.
It was concluded that efficiency and effectiveness explored the experience of culture in the work place. Many people tried to enhance efficiency and effectiveness among employees. Martiz and Blanch et al., studied organizational culture with creativity, effectiveness and efficiency of the building managers ${ }^{21}$. They concluded that there is a significant relationship between organizational culture, creativity, effectiveness and efficiency. The result is consistent with present research. In a previous study studied group, individual and organizational factors affecting on efficiency and effectiveness ${ }^{11}$. They concluded that time source; group communication system and organizational structure are effective on individual efficiency and effectiveness ${ }^{3}$. The result was in agreement with present research. Mosavi et al., studied organizational culture and stated that the organization should use efficient, sensitive and thoughtful employees to cope with threats and to apply opportunities $^{13}$. Such employees not only should perform their tasks but also, they have to show spontaneous behaviors thus they are valued by managers beyond job description. This event will 
influence directly on organizational effectiveness because managers cannot predict all possible activities the employees want to perform ${ }^{17}$.

Hypothesis 2: organizational culture has a significant effect on improvement of effectiveness of personnel of Shiraz University of medical science. Correlation coefficient of the variables is 0.938 and their significance level is 0.000 which is below 0.01 . Such hypothesis is confirmed by $99 \%$. Therefore, there is a significant relationship between organizational culture and effectiveness of personnel of Shiraz University of medical science. $\mathrm{H} 0$ is rejected and $\mathrm{H} 1$ is confirmed.
Thus, improvement of organizational culture increases effectiveness of personnel of Shiraz University of medical science. Flevy et al., studied the relationship between organizational culture and effectiveness of staffs of shipping organization development association and concluded that there was a positive and significant relationship between organizational culture and effectiveness ${ }^{16}$. The result was consistent with present research. Watson concluded that organizational culture had significant effect on the effectiveness of higher education institutes.

Table 4: Ranking effectiveness indicators of personnel of Shiraz University of medical science.

\begin{tabular}{lccccc}
\hline Efficiency indicator & Rank & $\begin{array}{c}\text { Mean } \\
\text { rank }\end{array}$ & $\begin{array}{c}\text { Freedom } \\
\text { degree }\end{array}$ & $\mathbf{X}^{\mathbf{2}}$ & $\begin{array}{c}\text { Significance } \\
\text { level }\end{array}$ \\
\hline Technology & 1 & 5 & 3 & 913.795 & 0.000 \\
Incentive & 2 & 3.95 & & & \\
Staffs' training & 3 & 2.86 & & & \\
Organizational culture & 4 & 2.19 & & & \\
\hline
\end{tabular}

Hypothesis 3: incentive has a significant effect on improvement of efficiency of personnel of Shiraz University of medical science. Correlation coefficient of the variables is 0.907 and their significance level is 0.000 which is below 0.01 . Such hypothesis is confirmed by $99 \%$. Therefore, there is a significant relationship between incentive and efficiency of personnel of Shiraz University of medical science. H0 is rejected and $\mathrm{H} 1$ is confirmed. Thus, proper incentive increases the efficiency of personnel of Shiraz University of medical science. Mohammadi et al., found that organizational factors such as organizational climate encouraged employees to collaborate and influenced on their efficiency ${ }^{12}$. This is consistent with present research. Their study concluded that lack of job motivation is considered as a problem for efficiency and effectiveness. Minchuk et al., studied efficiency, motivation and effectiveness and concluded that there was a significant difference in the small size of components of motivation and efficiency ${ }^{19}$. This was consistent with present research. The results of LSD test suggest that incentive is one of the important indicators of organizational efficiency and effectiveness. Veronika et al., studied efficiency and effectiveness and found that giving proper incentives to real authorities is an effective factor on increasing efficiency and effectiveness of suggestion system ${ }^{20}$. The individual who is active in suggestion system should be supported by managers. The result is consistent with present research. When the individual is being paid attention, he/she will try well in direction of offering suggestions.

Hypothesis 4: incentive factor has a significant effect on improvement of effectiveness of personnel of Shiraz University of medical science. Correlation coefficient of the variables is 0.915 and their significance level is 0.000 which is below 0.01 . Such hypothesis is confirmed by $99 \%$. Therefore, there is a significant relationship between incentive and effectiveness of personnel of Shiraz University of medical science. H0 is rejected and $\mathrm{H} 1$ is confirmed. Thus, improvement of incentives increases the effectiveness of personnel of
Shiraz University of medical science. Many researches show that lack of incentives for job performance reduces optimal implementation of works. Managers may believe that salaries are proper incentives for employees. Although, salary is an effective factor on maintenance and performance of employees, they want different and various incentives due to their performance. The incentive can be material or immaterial. Incentives can include smiling, verbal appreciation, shaking the head for satisfaction. Managers should develop favorable performance in organizations using various incentives.

Hypothesis 5: technology has a significant effect on improvement of efficiency of personnel of Shiraz University of medical science. Correlation coefficient of the variables is 0.897 and their significance level is 0.000 which is below 0.01. Such hypothesis is confirmed by $99 \%$. Therefore, there is a significant relationship between technology and efficiency of personnel of Shiraz University of medical science. H0 is rejected and $\mathrm{H} 1$ is confirmed. Thus, improvement of technology increases efficiency of personnel of Shiraz University of medical science. According to Alvani et al., the selection and application of a proper technology, as a mean for doing works, are effective on the increase or reduction of productivity. The selection of instruments, machineries, methods and other manufacturing instruments of products and services can be effective on reduction of costs and increase of organizational outputs. The results are consistent with present research. Peyala et al., studied the effect of technology on productivity, efficiency and effectiveness of libraries and concluded that technology played a positive role in reduction of concentration, improvement of education and increase of effective and efficient communications in the library. The result is in agreement with present research. Crowston et al., came up with the conclusion that there was a significant relationship between development of information and communication technology and organizational components. The development of information technology influences the 
activities of staffs and increases interorganizational communicating channels. Furthermore, the processes are improved and organizations as well as employees' efficiencies are increased. They are consistent with present research. Faramaleki et al., studied 238 manufacturing companies and concluded that use of technology had a significant effect on both company's structure and company's activities and performance ${ }^{11}$. Salamati et al., studied factors affecting efficiency and effectiveness of employees and managers and he concluded that technology was one of factors affecting efficiency and effectiveness ${ }^{5}$. This is in agreement with present research.

Hypothesis 6: technology has a significant effect on improvement of effectiveness of personnel of Shiraz University of medical science.

Hypothesis 7: Staffs' training has a significant effect on improvement of efficiency of personnel of Shiraz University of medical science. Correlation coefficient of the variable is 0.774 and their significance level is 0.000 which is below 0.01. Such hypothesis is confirmed by $99 \%$. Therefore, there is a significant relationship between staffs' training and efficiency of personnel of Shiraz University of medical science. H0 is rejected and $\mathrm{H} 1$ is confirmed. Thus, improvement of staffs' training increases efficiency of personnel of Shiraz University of medical science. According to Alvani et al., staffs' training for empowerment and efficiency of those working in governmental systems has been known as one of strategic programs of governmental management throughout the world because everything depends on the quality of staffs' training. IBM Company allocated 2 milliard dollars to staff training programs in 1985 . It is noteworthy that net profit of IBM was annually 6 milliard dollars. On average, Japanese employees participated in in-service programs within 28 days per year. The facts and statistics about training of human source in other countries show its importance in development of productivity. Ebrahimnejad et al., studied the relationship between strategic-expert knowledge share and productivity indicators of effectiveness and efficiency in insurance companies of Khorasan ${ }^{1}$. He came up with the conclusion that there was a positive and significant relationship between strategic-expert knowledge share and productivity indicators of effectiveness and efficiency. Therefore, it seems that favorable use of strategic-expert knowledge share can increase productivity of insurance industry. Hosseini $e t$ al., studied the relationship between training and organizational efficiency and effectiveness. He concluded that educational behaviors increased organizational efficiency and effectiveness as well as organizational health and they reduced corruption ${ }^{3}$. The result is consistent with present research. Jasim et al., stated in his research that staffs' training is one of factors that have been mentioned in many papers as a factor for increasing effectiveness of suggestion system which is consistent with present research ${ }^{17}$.

Hypothesis 8: Staff training has a significant effect on improvement of effectiveness of personnel of Shiraz University of medical science. Correlation coefficient of the variables is 0.820 and their significance level is
0.000 which is below 0.01. Such hypothesis is confirmed by $99 \%$. Therefore, there is a significant relationship between staffs' training and effectiveness of personnel of Shiraz University of medical science. $\mathrm{HO}$ is rejected and $\mathrm{H} 1$ is confirmed. Thus, improvement of staffs' training increases effectiveness of personnel of Shiraz University of medical science which is consistent with present research.

Hypothesis 9: prioritization of efficiency and effectiveness of personnel of Shiraz University of medical science (using Freidman test) shows the order of efficiency indicators of personnel of Shiraz University of medical science. Among indicators, organizational culture of personnel of Shiraz University of medical science (mean of 4) obtained the first place. Incentive (2.98), technological factors (2.02) and staffs' training (1) obtained respectively the second, third and the fourth places. The significance level of efficiency and effectiveness indicators of personnel of Shiraz University of medical science was equal to 0.000 at $95 \%$ level and the amount of $X^{2}$ was 697.282. In addition, prioritization of effectiveness indicator of personnel of Shiraz University of medical science shows that among research processes, technology with mean of 5 obtained the first place. Incentive with mean of 3.95 , staffs' training with mean of 2.86 and organizational culture obtained the second, third and fourth places respectively. Significance level of effectiveness indicator of personnel of Shiraz University of medical science is equal to $0.000(95 \%)$ and $\mathrm{X}^{2}$ is equal to 913.795 .

\section{AUTHOR'S CONTRIBUTION}

The manuscript was carried out, written, and approved in collaboration with all authors.

\section{ACKNOWLEDGEMENTS}

The authors extend their thanks and appreciation to the Islamic Azad University, Tehran, Iran to provide necessary facilities for this work.

\section{CONFLICT OF INTEREST}

No conflict of interest associated with this work.

\section{REFERENCES}

1. Ebrahimnejad E, Asa'di A. Studying the relationship between expert-strategic knowledge share and indicators of effectiveness and efficiency productivity in insurance companies of Khorasan, the first international conference of new paradigms of smart commercial and organizational management, Shahid Beheshti University, Tehran 2016.

2. Aghayi M, Aghayi R, Aghayi A. The role of occupational dimensions in efficiency and effectiveness of human source, organizational culture management 2014; 4: 809830. https://doi.org/10.3390/ijerph120606045

3. Hosseini SH, Heydari B. Studying the relationship between moral behavior and organizational efficiency and effectiveness, the seventh international conference of economy and management, Swede- Dalarna, ICOAC University communication center, governmental University of Dalarna 2016.

4. Khoshbat MA, Khaef Elahi A, Ahmadi AA. Identification and prioritization of factors of human source management affecting promotion of staffs' efficiency (case study: traffic cops), Traffic cops 2012; 1(1): 55-31. 
5. Salamati E. Studying the factors affecting efficiency and effectiveness of staffs and managers from view of transformation-oriented thinking, the third international conference of applied researches in management and accounting, Tehran University of Shahid Beheshti, 2015.

6. Shariatmadri A. The principles and philosophy of education, Amirkabir publications, 1985.

7. Saidi P, Nazari MR. The principles of management and supervision, Gorgan, Payam Pouya, Third edition 2008; 6.

8. Alagheband A, Effective leadership via face-to-face relationship between manager and staffs, quarterly of management of education 1994; 11.

9. Alagheband A. Theoretical basics and principles of educational management, Ravan publication, $11^{\text {th }}$ edition, Tehran. 1999.

10. Faridi A. The relationship between leadership style of principals and efficiency of physical education teachers of Garmi city, M.A thesis for sport management, Tehran, 2011. https://doi.org/10.1016/j.sbspro.2014.01.1260

11. Faramaleki AF, Hosseini M. Efficiency and effectiveness of ethical educational programs in the organization, ethics bulletin $2011 ; 17$ : 7-26.

12. Mohammadi AJ, Ghabeljoo M, Asghari M. The relationship between motivational factors and the increasing efficiency of staffs in Alborz University of medical science and therapeutic services, Zahedan medical science researches. 2010; 1(13): 51-62.

13. Mosavi SA. Studying the effect of in-service education on efficiency of high school principals, district 3, Ahvaz, M.A thesis, Payam Noor University of Tehran, 2013.

14. Mehdizadeh. Studying the relationship between human skills of managers and their effectiveness from views of middle-school principals of Birjand, M.A thesis, Shahid Beheshti University, 1996. https://doi.org/10.5539/gjhs.v7n2p38

15. Bianco M. Dacid. Suggestion System htm, 2006.

16. Flevy L, Mohammed A, Aftab R. Int J Quality Reli Manag 2015; 182-210. https://doi.org/10.18551/rjoas.2019-03.25

17. Jasim AA. Clients of conventional and Islamic banks in Bahrain: How they choose which bank to patronize. Int $\mathbf{J}$ Soc Econ 2009; 1089- 1112. https://doi.org/10.1108/03068290910992642

18. Malmendier U, Tate G, Yan J. Overconfidence and earlylife experiences: the effect of managerial traits on corporate financial policies. The J finance 2011; 66(5): 1687-1733. https://doi.org/10.1111/j.1540-6261.2011.01685.x

19. Minchuk, Yizhaq, Shlomo Mizrahi. The (in) effectiveness of procurement auctions in the public sector. Applied Economics Letters 24.4. 2017; 247-249. https://doi.org/10.1080/03003930.2016.1181059

20. Veronika I, Alexandra M, Karlheinz S. Suggestion systems in organizations: what motivates employees to submit suggestions? European J Innov Man 2010; 507-525.

21. M. Kabir H. Int J Islam Midd East Fin Manag. Impact of financial liberalization and foreign bank entry on Islamic banking performance 2013; 7-42.

22. Al-qadasy MKO, Babaqi AS, Al-Abyadh MM, Al-kaf AGA. Investigation of toxic metals pollution in water, sediment and fish at Aden coast, gulf of Aden, Yemen. Universal J Pharm Res. 2017; 2(6): 4249. https://doi.org/10.22270/ujpr.v2i6.R8

23. Pensri A. Designing a learning model using the STAD technique with a suggestion system to decrease Learners' weakness. Procedia - Social and behavioral sciences. 2014; 431-435. https://doi.org/10.1016/j.sbspro.2014.01.235 